\title{
Lung Growth and Airway Function after Lobectomy in Infancy for Congenital Lobar Emphysema
}

\author{
John T. McBride, Mary Ellen B. Wohl, Denise J. Strieder, Andrew C. JaCkson, \\ John R. Morton, Robert G. Zwerdling, N. Thorne Griscom, Salvador \\ Treves, Adrian J. Williams, and Samuel Schuster, Departments of Pediatrics, \\ Radiology, Pathology and Surgery, Children's Hospital Medical Center and \\ Harvard Medical School, Boston, Massachusetts 02115
}

\begin{abstract}
A B S T RACT To characterize the outcome of lobectomy in infancy and the low expiratory flows which persist after lobectomy for congenital lobar emphysema, 15 subjects with this history were studied at age 8-30 yr. Total lung capacity was normal in all, but higher values $(P<0.05)$ were observed in nine subjects with upper lobectomy than in five subjects with right middle lobectomy. Ratio of residual volume to total lung capacity was correlated $(P<0.05)$ with the amount of lung missing as estimated from normal relative weights of the respective lobes. $\mathrm{Xe}^{133}$ radiospirometry in eight subjects showed that the operated and unoperated sides had nearly equal volumes at total lung capacity, but that the operated side was larger than the unoperated side at residual volume. Perfusion was equally distributed between the two sides. Similar findings were detected radiographically in four other subjects. Forced expiratory volume in $1 \mathrm{~s}$ and maximal midexpiratory flow rate averaged 72 and $45 \%$ of predicted, respectively. Low values of specific airway conductance and normal density dependence of maximal flows in 12 subjects suggested that obstruction was not limited to peripheral airways. Pathologic observations at the time of surgery and morphometry of the resected lobes were not correlated with any test of pulmonary function.
\end{abstract}

This study was presented in part at the 89th Annual Meeting of the American Pediatric Association, May 1979, Atlanta Ga., and published in abstract form in 1979. Pediatr. Res. 13: 538.

Dr. Jackson's present address is California Primate Respiratory Center, University of California in Davis, Davis, Calif. 95616. Dr. Morton's present address is Prince of Wales Children's Hospital, University of New South Wales, Sydney, Australia, Dr. Zwerdling's new address is La Rabida Children's Hospital and Research Center, 65th Street at Lake Michigan, Chicago, Ill. 60649. Dr. Williams' present address is Wadsworth Hospital, University of California at Los Angeles, Los Angeles, Calif. 90073.

Received for publication 14 February 1980 and in revised form 20 June 1980.
These data show that lung volume can be completely recovered after lobectomy for congenital lobar emphysema in infancy. The volume increase occurs on the operated side, and probably represents tissue growth rather than simple distension. The response to resection is influenced by the particular lobe resected and may be associated with decreased lung recoil near residual volume. Low expiratory flows in these subjects could be explained by several mechanisms, among which a disproportion between airway and parenchymal growth in infancy (dysanaptic growth) is most compatible with our data.

\section{INTRODUCTION}

Following pneumonectomy or lobectomy, the remaining lung tissue grows and expands so that total lung volume returns toward normal $(1,2)$. Animal studies $(2-5)$ suggest that this response is most vigorous in the newborn period. Congenital lobar emphysema (CLE) ${ }^{1}$ is one of the few indications for lobectomy in human infants. Several studies $(6,7)$ have found that years after lobectomy for CLE, total lung capacity approximates mean predicted value, suggesting that there is a compensatory increase in lung volume after resection in infancy. Maximal expiratory flows, however, are reported to be abnormally low in these individuals $(6,7)$.

To document the extent and pattern of compensatory lung growth after lobectomy in infancy, we studied 15 individuals with a history of CLE. To elucidate the etiology of their decreased maximal flows, we evaluated lung recoil and the site of airway obstruction, reviewed

\footnotetext{
${ }^{1}$ Abbreviations used in this paper: CLE, congenital lobar emphysema; FEV, forced expiratory volume; MEFV, Maximum expiratory flow-volume; MMFR, Maximal mid-expiratory flow rate; $\dot{Q}$, perfusion; $R V$, residual volume; $S_{\text {aw }}$, specific conductance; TLC, total lung capacity; V, regional volume; $\dot{V}$, ventilation; VC, vital capacity; Viso $\dot{V}$, volume of isoflow; $\Delta \mathrm{V}_{\mathrm{max}_{50}}$, ratio of maximum expiratory flows at $50 \%$ $\mathrm{VC}$ on $\mathrm{He}-\mathrm{O}_{2}$ and room air.
} 
TABLE I

Clinical Data

\begin{tabular}{|c|c|c|c|c|c|c|}
\hline Subjects & Sex & $\begin{array}{l}\text { Age at } \\
\text { time of } \\
\text { surgery }\end{array}$ & $\begin{array}{c}\text { Age at } \\
\text { time of } \\
\text { study }\end{array}$ & Height & $\begin{array}{l}\text { Lobe } \\
\text { resected }\end{array}$ & $\begin{array}{c}\text { Estimated } \\
\text { loss }\end{array}$ \\
\hline & & & $y r$ & $\mathrm{~cm}$ & & $\% *$ \\
\hline 1 & M & $1 \mathrm{wk}$ & 8 & 131 & RML & 8 \\
\hline 2 & $\mathbf{M}$ & $6 \mathrm{mo}$ & 12 & 160 & RML & 8 \\
\hline 3 & $\mathbf{M}$ & $2 \mathrm{mo}$ & 14 & 168 & RML & 8 \\
\hline 4 & $\mathbf{M}$ & $7 \mathrm{mo}$ & 16 & 175 & RML & 8 \\
\hline 5 & $\mathbf{F}$ & $2 \mathrm{wk}$ & 17 & 154 & RML & 8 \\
\hline 6 & $\mathbf{M}$ & $8 \mathrm{mo}$ & 25 & 172 & RML & 8 \\
\hline 7 & $\mathbf{M}$ & $1 \mathrm{wk}$ & 11 & 151 & RUL & 15 \\
\hline 8 & $\mathbf{M}$ & $1 \mathrm{wk}$ & 11 & 134 & LUL & 22 \\
\hline 9 & M & $1 \mathrm{mo}$ & 16 & 165 & LUL & 22 \\
\hline 10 & $\mathbf{M}$ & $2 \mathrm{wk}$ & 14 & 167 & RUL & 20 \\
\hline 11 & M & $3 \mathrm{yr}$ & 19 & 176 & LUL & 17 \\
\hline 12 & M & $2 \mathrm{yr}$ & 32 & 178 & RUL & 20 \\
\hline 13 & $\mathbf{M}$ & $6 \mathrm{mo}$ & 20 & 177 & RUL, RML & 28 \\
\hline \multirow[t]{2}{*}{14} & $\mathbf{M}$ & $3 \mathrm{mo}$ & 16 & 161 & LUL & \\
\hline & & $6 \mathrm{mo}$ & & & RML & 30 \\
\hline \multirow[t]{2}{*}{15} & $\mathbf{M}$ & $2 \mathrm{wk}$ & 12 & 140 & LUL & \\
\hline & & 14 wk & & & LLL & 45 \\
\hline
\end{tabular}

* Percent of lung weight, based on normal weights of individual lobes (8).

† RML, right middle lobe; RUL, right upper lobe; LUL, left upper lobe; LLL, left lower lobe.

the pathology, and made morphometric measurements on sections of the resected lobes.

\section{METHODS}

We studied 15 of the 43 individuals operated for CLE at Children's Hospital Medical Center between 1947 and 1970. Of the remaining 28,4 had died, 12 could not be located, 3 were living outside New England, 2 declined to participate, and 7 were inappropriate for study because of associated abnormalities such as congenital heart disease.

All subjects had presented in early childhood with hyperlucent lobe on chest radiograph, displacing the remainder of the lung. In each case the surgeon described a distended lobe which did not deflate with expiration when the chest was opened. In one (patient 6) the lobe appeared to be twisted $180^{\circ}$ on its pedicle. In the others, no extrinsic obstruction was seen. The estimated amount of lung resected (8) ranged from $8 \%$ of total lung tissue for right middle lobectomy to $45 \%$ for left pneumonectomy (Table I). CLE rarely involves lower lobes (9) and only the subject with pneumonectomy (patient 15) had a lower lobe resection.

At the time of study, the subjects ranged in age from 8 to 32 yr. 11 reported no unusual respiratory symptoms since early childhood. Two had a history of asthma, one of whom (patient 1) was taking an oral theophylline preparation. Two others described mild dyspnea on exertion. None had had an upper respiratory infection in the $6 \mathrm{wk}$ preceding the tests.

Spirometry was performed with a water-sealed spirometer (W. E. Collins, Inc., Braintree, Mass.). Forced expiratory volume in $1 \mathrm{~s}\left(\mathrm{FEV}_{1}\right)$, maximal mid-expiratory flow rate (MMFR), and vital capacity (VC) were read from the best of three spirographic tracings.

Total lung capacity (TLC) was measured with a pressure- compensated, volume-displacement plethysmograph (J. H. Emerson Co., Cambridge, Mass.) by the method of Dubois et al. (10). TLC was measured six times and the results averaged. Residual volume (RV) was calculated by subtracting VC from TLC. Airway resistance was measured at functional residual capacity with a modification of the Dubois method (11). The inertance of the pneumotachometer, shutter, and tubing used to direct flow back into the plethysmograph caused flow to be out of phase with volume. To compensate for this phase lag, a signal proportional to acceleration was added to the flow signal until flow and volume were in phase. Specific conductance $\left(\mathrm{SG}_{\mathrm{aw}}\right)$ was calculated from resistance and the average of six separate determinations recorded. Results of spirometry, lung volumes, and specific conductance were compared with published normal values (12-15).

Maximal expiratory flow-volume (MEFV) curves were obtained on room air and after the subject had been breathing a mixture of $80 \%$ helium and $20 \%$ oxygen $\left(\mathrm{He}-\mathrm{O}_{2}\right)$ for $3 \mathrm{~min}$. Expiration was performed into a meteorological balloon contained in a rigid box. Flow was measured as airflow out of the box with a 4 Fleisch pneumotachometer (Dynasciences, Blue Bell, $\mathrm{Pa}$.) and volume with the plethysmograph. In 10 subjects, three curves on each gas mixture were filtered (16), averaged (17), and printed out by a digital computer (PDP 11-34, Digital Equipment Corp., Marlboro, Mass.). In five others (patient 2, 5, 8, 11,14) the curves were displayed on an oscilloscope, and the best on each gas mixture were photographed for analysis. With both methods the curves agreed within 5\% for VC. Room air MEFV curves with flow normalized by each subject's VC were compared with normal values (18). Room air and $\mathrm{He}-\mathrm{O}_{2}$ curves were matched at TLC to determine the ratio of maximum flows on $\mathrm{He}-\mathrm{O}_{2}$ and on air at $50 \%$ VC $\left(\Delta \dot{V}_{\max x_{0}}\right)$ and the volume of isoflow (VisoVi).

Static lung recoil was measured in six subjects and fre- 
quency dependence of dynamic compliance in four. A $10-\mathrm{cm}$, thin-walled latex balloon mounted on a polyethylene (PE 200) catheter was positioned in the middle third of the esophagus (19). Transpulmonary pressure measured between mouthpiece and esophageal balloon was related to plethysmographic volume during a slow, interrupted expiration from TLC immediately after three consecutive maximal inspirations. At least 20 volume-pressure points from three acceptable maneuvers were plotted on rectangular coordinates and the best pressure-volume curve fitted by eye.

Dynamic compliance was measured by the method of Mead et al. (20). Before each study, we synchronized the ballooncatheter-transducer system with the flow transducer at frequencies up to $15 \mathrm{~Hz}$. Subjects breathed through a large bore three-way valve and 4 Fleisch pneumotachometer (Dynasciences) with a bias flow of 0.5 liter/s. Following a maximal inspiration, they returned to functional residual capacity and breathed either spontaneously or in time with a metronome at $20,40,60$, and 90 breaths $/ \mathrm{min}$. At each frequency, subjects were able to keep functional residual capacity within $200 \mathrm{ml}$ and tidal volume within $100 \mathrm{ml}$ of spontaneous breathing values by observing plethysmographic volume displayed on an oscilloscope. Plethysmographic volume, air flow at the mouth, tidal volume obtained by integrating flow, and transpulmonary pressure were simultaneously recorded (model 7788a, Hewlett-Packard, Palo Alto, Calif.) Inspired tidal volume was divided by the difference in transpulmonary pressure measured between points of no flow at the beginning and at the end of inspiration. Dynamic compliance was plotted as a function of respiratory rate.

Closing volume was determined in five subjects by the helium bolus technique with an orifice helium analyzer (21). The concentration of helium was displayed against expired lung volume measured by a spirometer (Med-Science Electronics, St. Louis, Mo.). In eight other subjects, closing volume and slope of the alveolar plateau (slope of phase III) were measured with the single breath oxygen test (22). Following a maximal inspiration of $100 \%$ oxygen from $\mathrm{RV}$, flow and $\mathrm{N}_{2}$ concentration at the mouth were monitored simultaneously during expiration. The computer sampled signals for flow and $\mathrm{N}_{2}$ concentration simultaneously at 50 -ms intervals, integrated the flow signal for expired volume, and compensated for sampling delay and $90 \%$ rising time of the nitrogen analyzer (Nitrolyzer, Beckman Instruments, Inc., Fullerton, Calif.). Plots of $\mathrm{N}_{2}$ concentration against expired volume for three separate maneuvers were used to calculate the slope of phase III and the closing volume (23).

An aerosol of isoproterenol was given to all subjects but two, until pulse rate had increased by $15-20$ beats/min. Spirometry and measurements of lung volume and airway resistance were then repeated.

Radiospirometry was performed in eight subjects in the erect position with a gamma scintillation camera and on-line digital computer according to a modification (24) of the technique of Ball et al. (25). Regional volume (V), ventilation ( $\dot{V})$, and perfusion $(\dot{Q})$ were calculated for each lung and for the three zones into which each lung was divided. Relative volumes of the right and left sides, respectively, were determined after rebreathing at RV as well as at TLC. Inspiratory-expiratory film pairs or chest fluoroscopy were obtained in 14 subjects. Radiographs, interpreted by Dr. N. T. Griscom, who was unaware of individual surgical histories and physiological results, were rated for the relative volumes of the two sides at TLC and at RV, for abnormalities of perfusion, for localized air trapping, and for any other radiographic abnormalities.

Pathologists' reports of the resected lobe at the time of operation mentioned abnormalities in the quantity or distribution of bronchial cartilage in six cases (Table II). In one of these (patient 12) distortion of the bronchial architecture consistent with congenital bronchiectasis was also found. The bronchial cartilage was reported to be normal in six other cases, and was not described in three. Histologic slides or embedded

TABLE II

Morphometry, Pathology, and Surgical Observations

\begin{tabular}{|c|c|c|c|}
\hline \multirow[b]{2}{*}{ Subjects } & \multicolumn{2}{|c|}{ Radial alveolar count } & \multirow[b]{2}{*}{ Pathologic and/or surgical observations } \\
\hline & Observed \pm SEM & Predicted \pm SD & \\
\hline 1 & $4.9 \pm 0.36$ & $4.4 \pm 0.9$ & Bronchi unremarkable, interstitial emphysema \\
\hline 2 & $4.8 \pm 0.42$ & $4.4 \pm 0.9$ & Absent cartilage \\
\hline 3 & $5.7 \pm 0.38$ & $5.5 \pm 1.3$ & Normal cartilage \\
\hline 4 & $9.7 \pm 0.56$ & $6.6 \pm 1.7$ & Absent cartilage in lobar bronchus \\
\hline 5 & $8.9 \pm 0.27^{*}$ & $5.5 \pm 1.3$ & Normal cartilage \\
\hline 6 & $7.7 \pm 0.40$ & $6.6 \pm 1.7$ & Half twist in RML bronchus \\
\hline 7 & $7.3 \pm 0.51^{*}$ & $4.4 \pm 0.9$ & Decreased bronchial cartilage \\
\hline 8 & $5.8 \pm 0.31$ & $4.4 \pm 0.9$ & Absent cartilage \\
\hline 9 & $6.5 \pm 0.22$ & $4.4 \pm 0.9$ & Normal cartilage \\
\hline 10 & $11.3 \pm 0.83^{*}$ & $5.5 \pm 1.3$ & Decreased cartilage (surgical observation) \\
\hline 11 & $4.9 \pm 0.34$ & $7.3 \pm 1.4$ & Normal cartilage \\
\hline 12 & $6.0 \pm 0.58$ & $7.3 \pm 1.4$ & Absent cartilage, congenital bronchiectasis \\
\hline 13 & $7.0 \pm 0.45$ & $5.5 \pm 1.3$ & Normal airway caliber \\
\hline 14 & $6.5 \pm 0.45$ & $6.6 \pm 1.7$ & Normal cartilage, ? small bronchus \\
\hline \multirow[t]{2}{*}{15} & $5.8 \pm 0.36$ & $5.5 \pm 1.3$ & LUL: Absent cartilage \\
\hline & $8.3 \pm 0.49$ & $6.6 \pm 1.7$ & LLL: Bronchial obstruction, ? suture granuloma \\
\hline
\end{tabular}

Observed radial alveolar count and predicted value based on age at operation (26). A lobe was considered polyalveolar if the $95 \%$ confidence intervals of the observed mean (mean \pm 2 SEM) and predicted normal values (predicted mean \pm 2 SD) did not overlap.

* Polyalveolar lobes. 
blocks of tissue from the excised lobes were still available for all 15 subjects, and were reviewed by Dr. A. J. Williams. The number of alveoli per acinus was estimated by radial alveolar count (26). Mean value of at least 20 separate determinations of the number of alveolar walls between respiratory bronchioli and connective tissue septae was compared to agematched normal values (26).

Two-tailed Student's $t$ test and linear regression techniques were used in data analysis.

\section{RESULTS}

On physical examination, the subjects showed no evidence of muscle weakness or other abnormalities which might interfere with the performance or interpretation of the tests. Heights and weights were normal for age and evenly distributed about mean expected values. One subject (patient 14) had alpha-1-antitrypsin phenotype MS; all others were M.

$\mathrm{VC}$ was in the normal range in 13 of the 15 subjects, and TLC was normal in the 14 in whom it was measured (Table III). Nevertheless, the mean values of VC and TLC (94 and 93\% of predicted, respectively) were smaller than expected $(P<0.05$ and $P<0.025) . \mathrm{RV} /$ TLC was elevated only in the subject with left pneumonectomy.

MEFV curves on air showed that expiratory flows were $>1$ SD below mean values for healthy agematched individuals (Fig. 1). FEV $1, \mathrm{FEV}_{1} / \mathrm{VC}, \mathrm{MMFR}$, and/or $S_{a w}$ were below the normal range in 14

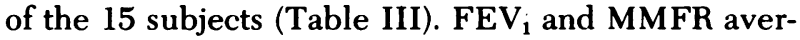
aged 73 and $45 \%$ of mean predicted values, respec- tively, and $\mathrm{SG}_{\mathrm{aw}} 0.11$ liter/s per $\mathrm{cm} \mathrm{H}_{2} \mathrm{O} /$ liter, whereas 0.14 is the lower limit of the normal range (14). Four subjects (patient $1,6,11,14$ ) had a component of reversible airway obstruction indicated by an increase of $\mathrm{FEV}_{1}>13 \%$ (27) after isoproterenol aerosol inhalation.

Individual values of $\Delta \dot{V}_{\text {maxso }}$ (Table IV) were in the range reported for a healthy population (28). Three subjects who had $\Delta \dot{V}_{\text {maxso }}$ below the predicted mean of 1.4 also had values of $V i s o \dot{V}$ greater than predicted for age, consistent with decreased density dependence of maximal expiratory flows.

Static pressure-volume curves (Fig. 2) were compared with curves of age-matched normal individuals obtained in this laboratory by the same technique and to the data of Turner et al. (29). One young subject (patient 7) had decreased lung recoil at high lung volumes, and one adult (patient 12) decreased recoil at low lung volumes. Four other subjects had normal pressurevolume curves. Dynamic compliance, measured in four subjects, fell as a linear function of breathing rate $(r$ $=-0.76$ to -0.80$)$. As compared to static values, dynamic compliance at $1 \mathrm{~Hz}$ fell by $28 \%$ in patient 3 , $65 \%$ in patient $6,35 \%$ in patient 7 , and $45 \%$ in patient 12 .

Closing volumes and the slope of phase III were within the expected range of normal (Table IV).

Radiospirometry showed that at TLC the operated lung was nearly normal in size compared with the unoperated lung (Table V). The operated side contributed a mean of $50 \%$ of total counts in six subjects with rightsided resections, and 46 and $47 \%$, respectively, in two

TABLE III

Lung Volumes, Flows, Airway Resistance, and Isoproterenol Response

\begin{tabular}{|c|c|c|c|c|c|c|c|c|c|c|c|}
\hline \multirow[t]{2}{*}{ Subjects } & \multicolumn{2}{|c|}{ TLC } & \multicolumn{2}{|c|}{ VC } & \multicolumn{3}{|c|}{ FEV, } & \multicolumn{2}{|c|}{ MMFR } & \multirow{2}{*}{$\begin{array}{c}\mathrm{SG}_{\mathrm{aw}} \\
\text { liter/s/cm } \\
\mathrm{H}_{2} \mathrm{O} / \text { liter }\end{array}$} & \multirow{2}{*}{$\begin{array}{l}\begin{array}{l}\triangle \mathrm{FEV}_{1} \text { with } \\
\text { isoproterenol }\end{array} \\
\text { \% base line }\end{array}$} \\
\hline & liter & $\% P^{*}$ & liter & $\% P^{*}$ & liter & $\% P !$ & $\% V C$ & liter/min & $\% P \$$ & & \\
\hline 1 & - & - & 1.69 & 85 & 0.92 & 58 & 54 & 27 & 19 & - & +63 \\
\hline 2 & 3.85 & 81 & 3.10 & 86 & 2.36 & 77 & 76 & 128 & 56 & 0.18 & - \\
\hline 3 & 4.68 & 88 & 3.91 & 93 & 2.76 & 81 & 71 & 134 & 53 & 0.15 & +5 \\
\hline 4 & 5.63 & 90 & 4.16 & 88 & 2.62 & 71 & 63 & 108 & 39 & 0.09 & +9 \\
\hline 5 & 3.73 & 91 & 3.23 & 103 & 2.39 & 85 & 74 & 132 & 63 & 0.13 & -1 \\
\hline 6 & 5.40 & 86 & 4.53 & 94 & 2.76 & 72 & 61 & 102 & 38 & 0.08 & +19 \\
\hline 7 & 4.09 & 103 & 3.28 & 108 & 2.44 & 92 & 74 & 128 & 63 & 0.11 & -2 \\
\hline 8 & 2.86 & 103 & 2.30 & 108 & 1.64 & 85 & 71 & 87 & 59 & - & - \\
\hline 9 & 5.15 & 99 & 3.77 & 95 & 2.22 & 68 & 59 & 94 & 34 & 0.12 & +9 \\
\hline 10 & 5.39 & 100 & 4.27 & 104 & 2.15 & 61 & 50 & 58 & 29 & 0.10 & +8 \\
\hline 11 & 6.07 & 92 & 4.85 & 93 & 2.79 & 67 & 57 & 134 & 62 & 0.08 & +28 \\
\hline 12 & 6.56 & 98 & 5.04 & 101 & 3.26 & 81 & 65 & 128 & 50 & 0.13 & +7 \\
\hline 13 & 6.47 & 98 & 4.93 & 97 & 3.18 & 78 & 65 & 115 & 52 & 0.11 & +4 \\
\hline 14 & 3.89 & 80 & 2.80 & 76 & 1.42 & 46 & 51 & 50 & 21 & 0.10 & +13 \\
\hline 15 & 2.72 & 87 & 1.84 & 77 & 1.40 & 63 & 76 & 71 & 42 & 0.08 & +2 \\
\hline
\end{tabular}

* Percent of mean predicted values: reference (12) for ages 1-17 yr, (13) for ages over $17 \mathrm{yr}$. ‡ Percent of mean predicted values: reference (14) for ages 1-17 yr, (13) for ages over $17 \mathrm{yr}$. $\$$ Percent of mean predicted values: reference (14) for ages 1-17 yr, (15) for ages over $17 \mathrm{yr}$. 


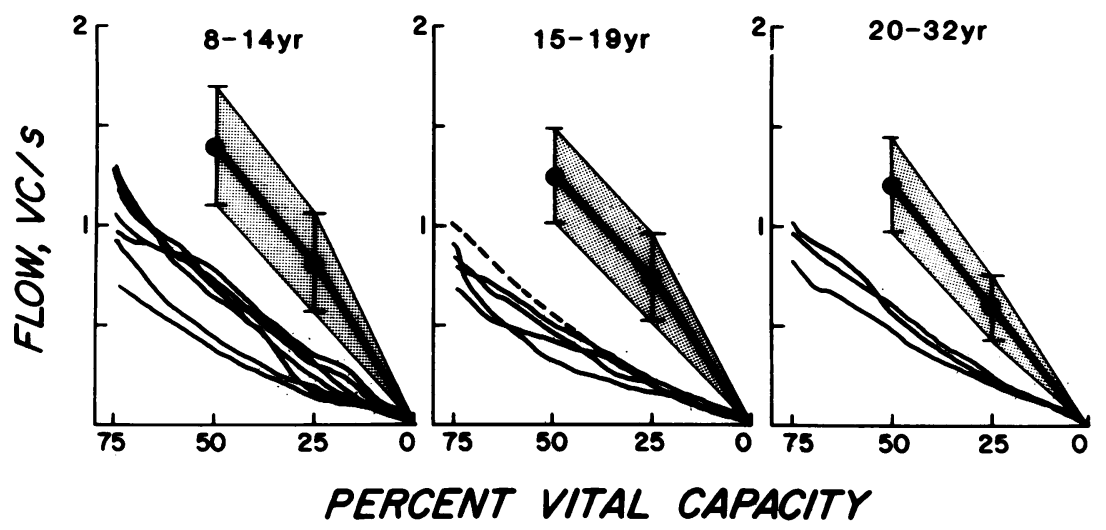

FIGURE 1 Maximum expiratory flow volume curves. MEFV curves on air with flow expressed as vital capacities per second. Mean values for age-matched healthy males (18) of maximum flow at 50 and $25 \%$ of vital capacity \pm SD are indicated by bars and shaded areas extrapolated from these values. Interrupted curve is that of the only female subject.

subjects with left-sided resections. With our technique, the right side normally contributes $53 \%$ of the total counts detected at TLC and the left side 47\% (30). At RV the operated side was responsible for a greater share of the total counts than at TLC. Pulmonary blood flow and ventilation were distributed in proportion to volume on the right and left sides, as indicated by normal $\mathbf{Q} / \mathrm{V}$ and $\dot{\mathrm{V}} / \mathrm{V}$ ratios (Table $\mathrm{V})$. Vertical gradients of perfusion and ventilation were normal on both sides. Two of eight subjects (patients 10 and 12) had small areas of delayed washout on the operated side.

Radiographic estimates of the volumes of the two sides at TLC and RV agreed closely with radiospirometric data. In two of the four subjects who had radiographs but no radiospirometry, relative volume of

TABLE IV

Density Dependence, Closing Volume, and Slope of Phase III

\begin{tabular}{ccrcc}
\hline Subjects & $\Delta \dot{V}_{\text {mexw }}$ & Viso & $\begin{array}{c}\text { Closing } \\
\text { volume }\end{array}$ & $\begin{array}{c}\text { Slope of } \\
\text { phase III }\end{array}$ \\
\hline & & & $\% V C$ & $\% N_{2} / l i t e r$ \\
1 & 1.47 & 12 & - & - \\
2 & 1.46 & 4 & 0 & - \\
3 & 1.28 & 2 & 6 & 1.1 \\
4 & 1.37 & 6 & 5 & 0.8 \\
5 & 1.39 & 39 & 12 & - \\
6 & 1.51 & 12 & 9 & 0.7 \\
7 & 1.47 & 8 & 9 & 0.7 \\
8 & 1.67 & 8 & - & - \\
9 & 1.52 & 8 & 15 & 1.7 \\
10 & 1.47 & 5 & 10 & 0.9 \\
11 & 1.68 & 0 & 6 & - \\
12 & 1.19 & 31 & 11 & 1.7 \\
13 & 1.34 & 11 & 0 & - \\
14 & 1.27 & 26 & 0 & - \\
15 & 1.54 & 7 & 13 & 0.8 \\
\hline
\end{tabular}

the operated side was normal or only minimally decreased at TLC and was increased at RV. Air trapping was identified in one (patient 10) of the two subjects who had delayed washout by radiospirometry and was confined to a small region of the operated side.

Lung volumes had no correlation with the estimated amount of lung removed but did depend upon the particular lobe resected. In nine cases of upper lobectomy, TLC averaged $96 \%$ of mean predicted value. In five cases of right middle lobectomy, TLC averaged $87 \%$ of mean predicted value, significantly smaller than expected $(P<0.01)$ and smaller than the mean TLC observed after upper lobectomy $(P<0.05)$. Only RV/TLC correlated $(P<0.05)$ with the estimated amount of lung resected (Fig. 3).

No statistical relationship between the age at surgery and tests of airway function could be established. Nevertheless, the three subjects with the highest values of $\mathrm{FEV}_{1}$ were operated within the first 2 wk of life.
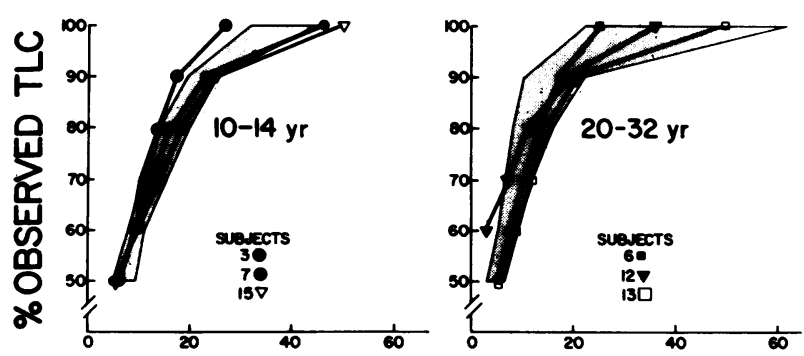

STATIC LUNG RECOIL, $\mathrm{cm} \mathrm{H} \mathrm{H}_{2} \mathrm{O}$

FIGURE 2 Lung pressure-volume curves. Data of three children and three adults are presented with lung volume expressed as a percent of observed TLC. Shaded areas represent range of values for 8 healthy males 10-14 yr of age in our laboratory, and 12 males $20-32$ yr of age from the data of Turner et al. (29). 
TABLE V

Share of Function on Operated Side by Radiospirometry

\begin{tabular}{|c|c|c|c|c|c|}
\hline \multirow[b]{2}{*}{ Subjects } & \multicolumn{2}{|c|}{ Volume at TLC } & \multirow{2}{*}{$\frac{\text { Volume at RV }}{\text { Observed }}$} & \multirow[b]{2}{*}{ Q́/N AT TLC } & \multirow[b]{2}{*}{$\dot{\mathrm{V}} / \mathrm{V}$ AT TLC } \\
\hline & Predicted & Observed & & & \\
\hline & \multicolumn{2}{|c|}{$\%$} & $\%$ & & \\
\hline 2 & 53 & 48 & - & 1.00 & 0.98 \\
\hline 3 & 53 & 53 & 59 & 1.06 & 0.97 \\
\hline 7 & 53 & 50 & 55 & 1.00 & 0.98 \\
\hline 9 & $47^{*}$ & 46 & 50 & 0.98 & 1.04 \\
\hline 10 & 53 & 52 & 57 & 0.92 & 0.91 \\
\hline 11 & $47^{*}$ & 47 & 51 & 0.94 & 0.99 \\
\hline 12 & 53 & 51 & 57 & 0.87 & 0.92 \\
\hline 13 & 53 & 48 & 52 & 1.10 & 1.17 \\
\hline Mean values & 51.5 & 49.5 & 54.4 & 0.98 & 1.00 \\
\hline
\end{tabular}

* Subjects with left-sided resections.

On the basis of radial alveolar counts (Table II), 3 resected lobes had too many alveoli per acinus (polyalveolar lobe), and 12 had a normal number of alveoli per acinus for the subject's age at surgery. It was not possible physiologically to distinguish between these two groups of individuals. Neither was it possible to correlate lung volumes or tests of airway function with reported abnormalities of airway cartilage in the resected lobes.

\section{DISCUSSION}

Lung volumes. The normal lung volumes in these individuals indicate that lobectomy in infancy can be followed by a vigorous compensatory increase in lung size. Although overestimation of lung volumes by plethysmography has been observed during asthmatic attacks (31), such errors, which have been attributed to

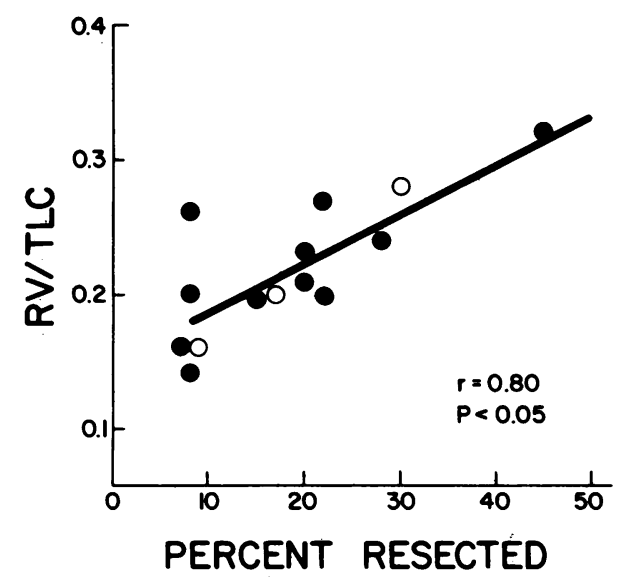

FIGURE 3 RV/TLC as function of lung resected. Open circles represent subjects 6,11 , and 14 , who had reversible airways obstruction. widespread airway closure, are unlikely in our subjects who had normal closing volumes. Our subjects did not differ in race or physical stature from the populations used for comparisons $(12-13)$.

The magnitude of volume compensation appeared to depend on the particular lobe resected. The significant difference between the nearly complete compensation after upper lobectomy and the absence of compensation after right middle lobectomy could not be explained by consideration of age at the time of surgery, clinical presentation, structure of the resected lobes, or degree of airway obstruction present at the time of study. Therefore, volume compensation in infancy, although nearly complete after upper lobectomy, may not be stimulated by removal of the right middle lobe. A comparable phenomenon has been observed after experimental surgery in dogs (32), in whom upper lobectomy was consistently followed by less vigorous volume compensation than lower lobectomy. Although the particular lobe associated with compensation was different in dogs than in infants with CLE, it appears that anatomic factors other than lobe size influence the compensatory response after resection.

In animal models, the lung remaining after pneumonectomy, lobectomy, or lobar collapse attains the volume expected for body weight, and DNA, RNA, and protein contents of the lung increase concomitantly $(3$, $4,33,34)$. When resection is performed in young rather than adult animals, the compensatory response is faster $(2,3,35)$ and is associated with a greater increase in cell number $(4)$, gas exchanging surface area $(3,5)$ and alveolar number (5). We believe that these differences reflect a greater potential for lung growth in younger animals.

After lobectomy in human adults there is a permanent loss of lung volume and function (36-38). After lobectomy in childhood, Filler (39) observed only modest 
volume compensation, and Cook and Bucci (40) could find no evidence of compensatory growth. Two groups of five children were previously studied after surgery in infancy for CLE $(6,7)$. In both groups, as in our subjects, TLC was found to be normal, suggesting that lung volume is more completely recovered after lobectomy in infancy than later in life. However, age may not be the only factor accounting for this difference if the particular lobe resected influences volume compensation in childhood. Although the majority of reported subjects with CLE, and all of our subjects with volume compensation, had lost upper lobes, only two of the nine studied by Cook and Bucci had had upper lobectomies.

Volume compensation in our subjects resulted from a unilateral increase in the volume of lobes remaining on the operated side. Of the factors which may be involved in determining lung growth (41), only mechanical stretch seems likely to explain this confinement of compensatory growth to the operated side. Although chemical mediators $(42,43)$ may initiate tissue growth and cellular division after resection, mechanical factors may modify the response by encouraging growth on the operated side or by limiting growth on the other side. There is considerable evidence that decreased mechanical stretch limits lung growth and alveolar multiplication $(2,33,44,45)$. Evidence that increased mechanical stretch facilitates lung growth is limited. In children with congenital diaphragmatic hernia, the affected lung, which is small and hypoplastic at birth, attains normal volume years after repair of the hernia (46) even though perfusion is permanently reduced (47). After bilobectomy in rats, both the operated and unoperated lung participate in compensatory growth (34). In such animal models, however, the compliant mediastinum may not allow pleural pressure to be more negative on the operated than the unoperated side.

The normal distribution of blood flow between both lungs in our subjects indicates that pulmonary vascular resistance was similar on the two sides, and suggests that the vascular bed of the operated lung had grown in proportion to the compensatory increase in lung volume. Therefore, the response to resection appeared to involve more than simple distension of the operated side. Previous studies of lung function after lobectomy in infancy for CLE $(6,7)$, in spite of reporting normal TLC, concluded that the volume increase was accomplished by distension rather than tissue growth. This conclusion was based on measurements of diffusing capacity in the low normal range, and increased RV. We did not measure diffusing capacity, and our subjects with greater volume compensation had higher values of RV/TLC (Fig. 3). However, RV was well within the normal range in all but one of our subjects, further indicating that the volume increase of the operated lung involved growth.
Lung elastic recoil. Normal pressure-volume curves in four of the six subjects studied and normal closing volumes in all indicate that lung elastic properties are normal in many subjects with a history of CLE. Nevertheless, significantly higher values of RV/TLC in subjects with more extensive resection (Fig. 3) suggest that decreased recoil at low volumes was associated with compensatory growth. The consistent failure of the operated side to empty as completely as the other side by radiospirometry is evidence that recoil was lower on the side involved in volume compensation. Decreased recoil could reflect an abnormal elastin network (48) or abnormally large airspaces on the operated side (if volume compensation involved airspace enlargement). Early airway closure on the operated side could also explain these observations, but closing volumes were normal. After contralateral pneumonectomy in the rat, lung recoil is also abnormal near RV (3).

Airway function. Measurements of maximal expiratory flows and airway conductance confirmed persistent airway obstruction in most individuals operated for CLE. Four of our subjects had a reversible component of airway obstruction. In the others there was little response to isoproterenol, density dependence was normal, $\mathrm{SG}_{\mathrm{aw}}$ was reduced, and RV/TLC was not elevated. Therefore, decreased flows could not be attributed to asthma, to obstruction limited to the peripheral airways, or to abnormalities of elastic recoil.

The physiologic findings in this study are consistent with a disproportion between airway size and lung volume, as could result from unequal growth of airways and lung parenchyma. Such disproportionate growth, referred to as dysanapsis (49), has been proposed to explain the variability of maximal flows among healthy individuals (49), the abnormally low flows observed in high altitude natives who have large lungs (50), and the difference between flows of males and females (51). Unequal growth of airways and parenchyma has been documented after bilobectomy in animals (34).

In our subjects, airways could have grown less than lung parenchyma either during the compensatory response after surgery or before surgery, when the healthy lung was displaced by the emphysematous lobe. Dysanapsis during compensatory growth, by compromising airway function primarily on the operated side, may have contributed to the frequency dependence of compliance observed in several subjects. Such compensatory growth is, however, unlikely to have been the only cause of decreased flows, since subjects with middle lobectomy, who had no evidence of volume compensation, were as obstructed as other subjects. Dysanapsis could have occurred before surgery if compression by the large abnormal lobe adversely affected airway growth more than parenchymal growth. This mechanism would affect airways on both sides and 
would explain the presence of airway obstruction independent of the extent of compensatory response, the amount of lung tissue resected, and the pathologic and morphometric findings. If airway growth were inhibited before surgery, early lobectomy might be associated with better residual airway function. In our subjects the distribution of ages at surgery was narrow and the timing of surgery was not significantly related to any parameter of airway function. Nevertheless, the three subjects with the highest $F E V_{1}$ were operated in the first few weeks of life.

Morphometry and pathology. The distinct morphometric and pathologic patterns that have been identified in resected lobes of children with CLE suggest that this syndrome may not represent a single pathophysiologic entity. Reid (52) and co-workers have documented that some such lobes contain a greater than normal number of alveoli (polyalveolar lobes) or too few alveoli (hypoplastic lobes). Still other lobes have normal alveolar numbers, suggesting that emphysema in these cases is the result of processes unrelated to alveolar development, probably including lobar bronchial obstruction as in subject 6 .

In designing this study, we hypothesized that if the congenital defect responsible for the lobar emphysema were also responsible for the normal lung volumes or abnormally low flows later in life, then measurements of lung function might be related to the structure of the resected lobes. Histologic slides or embedded blocks were available for each of the 15 subjects. Because the lobes had been fixed at various levels of inflation and because the amount of tissue available was limited, direct morphometric estimates of alveolar number and size could not be made. We chose, therefore, to use the Emery-Mithal method (26), which allows estimates of alveolar development unaffected by techniques of fixation. There was no statistical difference in physiologic tests between the 3 subjects with a polyalveolar lobe and the 12 with normal numbers of alveoli. With any morphometric technique, however, identifying a polyalveolar lobe may be imperfect in subjects operated beyond the first months of life; alveoli in a polyalveolar lobe may not continue to proliferate after birth, and a lobe with too many alveoli at birth may have a normal number of alveoli at the time of surgery.

Campbell (53) has reported abnormalities of airway cartilage in resected lobes from some infants with CLE, and has suggested that this abnormality may cause the airway obstruction responsible for lobar emphysema. Histologic sections available to us did not include large airways in sufficient numbers to quantify airway cartilage. However, reports from the time of surgery did include evaluations of airway cartilage based on the gross examination and dissection of the resected lobe. No difference in pulmonary function could be estimated between subjects whose resected lobe had ab- normal cartilage, and those with normal cartilage, as judged by the surgical pathologist.

Summary. The clinical well-being of our subjects attests to the good prognosis of children operated for CLE who have no associated congenital abnormalities. Their normal lung volumes, radiographs, and radiospirometric data suggest that compensatory growth had occurred in response to the lobectomy in infancy. Low expiratory flows, the only persistent abnormality, appear unrelated to peripheral airways obstruction or decreased elastic recoil in most of these individuals, and may represent dysanaptic growth of airways and lung parenchyma, although a diffuse congenital abnormality in the airways cannot be excluded.

\section{ACKNOWLEDGMENTS}

The authors thank Mr. Thomas Wheeler and Ms. Carolyn Quinn for valuable technical assistance, and Dr. Lynne Reid for suggestions regarding morphometric techniques and interpretation of morphometric data. This work was supported by grant HL-15526 and research traning grant HL-07010, from the National Heart, Lung, and Blood Institute, U. S. Public Health Service, and a Pulmonary Research Fellowship (Dr. Morton) from the Parker B. Francis Foundation.

\section{REFERENCES}

1. Bremer, J. L. 1937. The fate of the remaining lung tissue following lobectomy or pneumonectomy.J. Thorac. Surg. 6: $336-342$.

2. Cohn, R. 1939. Factors affecting the postnatal growth of the lung. Anat. Rec. 75: 195-205.

3. Buhain, W. J., and J. S. Brody. 1973. Compensatory growth of the lung following pneumonectomy. J. Appl. Physiol. 35: 898-902.

4. Inselman, L. S., R. B. Mellins, and J. A. Brasel. 1977. Effect of lung collapse on compensatory lung growth. $J$. Appl. Physiol. 43: 27-31.

5. Holmes, C., and W. M. Thurlbeck. 1979. Normal lung growth and response after pneumonectomy in rats at various ages. Am. Rev. Respir. Dis. 120: 1125-1136.

6. Demuth, G. R., and H. Sloan. 1966. Congenital lobar emphysema: long-term effects and sequelae in treated cases. Surgery (St. Louis). 59: 601-607.

7. Eigen, H., R. J. Lemen, and W. W. Waring. 1976. Congenital lobar emphysema: long-term evaluation of surgically and conservatively treated children. Am. Rev. Respir. Dis. 113: $823-830$.

8. Massion, W. H., D. R. Caldwell, M. A. Early, and J. A. Schilling. 1962. The relationship of dry lung weights to pulmonary function in dogs and humans. J. Surg. Res. 2: 287-292.

9. Murray, G. F. 1967. Congenital lobar emphysema. Surg. Gynecol. Obstet. 124: 611-625.

10. DuBois, A. B., S. Y. Botelho, G. N. Bedell, R. Marshall, and J. H. Comroe, Jr. 1956. A rapid plethysmographic method for measuring functional residual capacity in normal subjects. J. Clin. Invest. 35: 322-335.

11. Mead, J. 1960. Volume displacement body plethysmograph for respiratory measurements in human subjects. J. Appl. Physiol. 15: 736-740.

12. Cook, C. D., and J. F. Hamann. 1961. Relation of lung volume to age in healthy persons between the ages of 5 and 38 years. J. Pediatr. 59: 710-714. 
13. Boren, H. G., R. C. Cory, and J. C. Syner. 1966. Veterans Administration-Army cooperative study of pulmonary function. II. Lung volume and its subdivisions in normal men. Am. J. Med. 41: 96-114.

14. Weng, T. R., and H. Levison. 1969. Standards of pulmonary function in children. Am. Rev. Respir. Dis. 99: 879-894.

15. Bates, D. V., P. T. Macklem, and R. V. Christie. 1971. Respiratory Function in Disease. W. B. Saunders, Philadelphia. 93-94.

16. Bruce, E. N., and A. C. Jackson. 1980. Smoothing of MEFV curves by digital filtering of flow as a function of volume. J. Appl. Physiol. 48: 202-206.

17. Tien, T., E. A. Elliot, and J. Mead. 1979. Variability of the configuration of maximum expiratory flow-volume curves. J. Appl. Physiol. 56: 565-570.

18. Knudson, R. J., R. C. Slatin, M. D. Lebowitz, and B. Burrows. 1976. Maximal expiratory flow-volume curve: normal standards, variability and effects of age. Am. Rev. Respir. Dis. 113: 587-600.

19. Milic-Emili, J., J. Mead, J. M. Turner, and E. M. Gauser. 1964. Improved technique for estimating pleural pressure from esophageal balloons. J. Appl. Physiol. 19: 207-211.

20. Mead, J., I. Lindgren, and E. A. Gaensler. 1955. The mechanical properties of the lungs in emphysema.J. Clin. Invest. 34: 1005-1016.

21. Green, M., D. M. Travis, and J. Mead. 1972. A simple measurement of phase IV ("closing volume") using a critical orifice helium analyzer. J. Appl. Physiol. 33: 827-830.

22. Fowler, W. S. 1949. Lung function studies. III. Uneven pulmonary ventilation in normal subjects and in patients with pulmonary disease. J. Appl. Physiol. 2: 283-299.

23. Suggested standardized procedures for closing volume determinations. 1973. Division of Lung Diseases, National Heart and Lung Institute, Bethesda. 1-9.

24. Treves, S., D. J. Strieder, and S. J. Adelstein. 1973. Scintillation camera radiospirometry. Prog. Nucl. Med. 3: 149-165.

25. Ball, W. C., P. B. Stewart, L. G. S. Newsham, and D. V. Bates. 1962. Regional pulmonary function studies with Xenon 133. J. Clin. Invest. 41: 519-531.

26. Emery, J. L., and A. Mithal. 1960. The number of alveoli in the terminal respiratory unit of man during later intrauterine life and childhood. Arch. Dis. Child. 35: 544-547.

27. Watanabe, S., A. D. Renzetti, R. Begin, and A. H. Bigler. 1974. Airway responsiveness to a bronchodilator aerosol. II. Normal human subjects. Am. Rev. Respir. Dis. 109: 530-537.

28. Dosman, J., F. Bode, J. Urbanetti, R. Martin, and P. T Macklem. 1975. The use of helium-oxygen mixture during maximum expiratory flow to demonstrate obstruction in small airways in smokers. J. Clin. Invest. 55: 1090-1099.

29. Turner, J. M., J. Mead, and M. E. B. Wohl. 1968. Elasticity of human lungs in relation to age. J. Appl. Physiol. 25: 664-671.

30. Treves, S., D. S. Ahnberg, R. Laguarda, and D. J. Strieder. 1974. Radionuclide evaluation of regional lung function in children. J. Nucl. Med. 15: 582-587.

31. Brown, R., R. H. Ingram, and E. R. McFadden. 1978 Problems in the plethysmographic assessment of changes in total lung capacity in asthma. Am. Rev. Respir. Dis. 118: $685-692$

32. Schilling, J. A. 1965. Pulmonary resection and sequelae of thoracic surgery. Handb. Physiol. 2: 1531-1552.

33. Cowan, M. J., and R. G. Crystal. 1975. Lung growth after unilateral pneumonectomy. Quantitation of collagen synthesis and content. Am. Rev. Respir. Dis. 111: 267-277.
34. Burri, P. H., and S. Sehovic. 1979. Adaptive response of the rat lung after bilobectomy. Am. Rev. Respir. Dis. 119: 769-783.

35. Nattie, E. E., C. W. Wiley, and D. Bartlett. 1974. Adaptive growth of the lung following pneumonectomy in rats. J. Appl. Physiol. 37: 491-495.

36. Limburg, M. 1954. Interpretation of bronchospirographic examinations after pulmonary resections. Acta. Tuberc. Scand. 29: 237-244.

37. Etsten, B. E., R. H. Overholt, J. H. Walker, and R. N. Reynolds. 1953. Pulmonary function after segmental pulmonary resection for bronchiectasis. N. Engl.J. Med. 248: 81-86.

38. Kamener, R., M. R. Becklake, H. Goldman, and M. McGregor. 1958. Respiratory function following segmental resection of the lung for bronchiectasis. Am. Rev. Tuberc. Pulm. Dis. 77: 209-220.

39. Filler, J. 1964. Effects upon pulmonary function of lobectomy performed during childhood. Am. Rev. Respir. Dis. 89: 801-810.

40. Cook, C. D., and G. Bucci. 1961. Studies of respiratory physiology in children. IV. The late effects of lobectomy on pulmonary function. Pediatrics. 28: 234-242.

41. Thurlbeck, W. M. 1975. Postnatal growth and development of the lung. Am. Rev. Respir. Dis. 111: 803-844.

42. Romanova, L. K., and I. A. Zhikhareva. 1972. On the humoral regulation of restorative growth in the lungs, kidneys, and liver. Biull. Eksp. Biol. Med. 73: 84-87.

43. Smith, B. T., W. Galaugher, and W. M. Thurlbeck. 1980. Serum from pneumonectomized rabbits stimulates alveolar type II cell proliferation in vitro. Am. Rev. Respir. Dis. 121: 701-708.

44. Gaensler, R. A., and J. W. Strieder. 1951. Progressive changes in pulmonary function after pneumonectomy: the influence of thoracoplasty, pneumothorax, oleothorax, and plastic sponge plombage on the side of pneumonectomy. J. Thorac. Surg. 22: 1-34.

45. Davies, G., and L. Reid. 1971. Effect of scoliosis on growth of alveoli and pulmonary arteries and on right ventricle. Arch. Dis. Child. 46: 623-632.

46. Wohl, M. E. B., N. T. Griscom, D. J. Strieder, S. R. Schuster, S. Treves, and R. G. Zwerdling. 1977. The lung following repair of congenital diaphragmatic hernia J. Pediatr. 90: 405-414.

47. Kitagawa, M., A. Hislop, E. A. Boyden, and L. Reid. 1973. Lung hypoplasia in congenital diaphragmatic hernia. A quantitative study of airway, artery and alveolar development. Br. J. Surg. 58: 342-346.

48. Brody, J. S. 1975. Time course of and stimuli to compensatory growth of the lung after pneumonectomy. J. Clin. Invest. 56: 897-904

49. Green, M., J. Mead, and J. M. Turner. 1974. Variability of maximum expiratory flow-volume curves. J. Appl. Physiol. 37: 67-74.

50. Brody, J. S., S. Lahiri, M. Simpser, E. K. Motoyama, and R. Velasquez. 1977. Lung elasticity and airway dynamics in Peruvian natives to high altitude. J. Appl. Physiol. 42: 245-251.

51. Mead, J. 1980. Dysanapsis in normal lungs assessed by the relationship between maximal flow, static recoil and vital capacity. Am. Rev. Respir. Dis. 121: 339-342.

52. Reid, L. 1977. The lung: its growth and remodeling in health and disease. Am. J. Roentgenol. Radium Ther. Nucl. Med. 129: 777-788.

53. Campbell, P. E. 1969. Congenital lobar emphysema, etiological studies. Aust. Paediatr. J. 5: 226-233. 